\title{
(- OPEN ACCESS \\ Mortality in the United States from self-injury surpasses diabetes: a prevention imperative
}

\author{
Ian R H Rockett, ${ }^{1}$ Eric D Caine, ${ }^{2}$ Hilary S Connery, ${ }^{3,4}$ Shelly F Greenfield ${ }^{3,4}$
}

'Department of Epidemiology, The Injury Control Research Center, West Virginia University, Morgantown, West Virginia, USA

${ }^{2}$ Department of Psychiatry, The Injury Control Research Center for Suicide Prevention, University of Rochester Medical Center, Rochester, New York, USA

${ }^{3}$ Division of Alcohol and Drug Abuse, McLean Hospital, Belmont, Massachusetts, USA ${ }^{4}$ Department of Psychiatry, Harvard Medical School, Boston, Massachusetts, USA

\section{Correspondence to} Dr lan R H Rockett, Department of Epidemiology, School of Public Health, West Virginia University, Morgantown, WV 26506, USA; rockett@hsc.wvu.edu

Received 24 May 2018 Revised 13 July 2018 Accepted 18 July 2018 Published Online First 27 August 2018

Check for updates

(C) Author(s) (or their employer(s)) 2019. Re-use permitted under CC BY-NC. No commercial re-use. See rights and permissions. Published by BMJ.

To cite: Rockett IRH Caine ED, Connery HS, et al. Inj Prev 2019:25:331-333.

\section{ABSTRACT}

This report uses an enhanced conceptualisation of self-injury mortality (SIM), which comprised registered or known suicides by any method and estimated non-suicide deaths from opioid and other drug selfintoxication. SIM surpassed diabetes as a cause of death in the USA in 2015. The gap expanded in 2016 with respective rates of 29.1 and 24.8 per 100000 population. Facing similar social and psychologically complex health problems to SIM, the USA has initiated and sustained successful broad-based prevention efforts that have reduced deaths from cardiovascular diseases, smoking-related lung cancer, HIV and motor vehicular injury — given both necessary epidemiological understanding to define the problem and sufficient political will to address it. Development of strategies to prevent SIM will be facilitated by focusing on factors that are common risks for diverse outcomes. Like premature mortality frequently associated with diabetes, deaths from self-injurious behaviours are preventable.

Declining life expectancy in the USA ${ }^{1}$ can be attributed to increasing mortality due to suicides, drug intoxications ('overdoses' and mixed drug effects) and alcohol-associated disorders. ${ }^{2}$ A comparative study showed that the rising rate of estimated self-injury mortality (SIM) — a composite of registered suicides by all methods and estimated non-suicide deaths from drug self-intoxicationconverged in 2014 at 24 deaths per 100000 population with mortality from diabetes, ${ }^{3}$ officially the seventh leading cause of death behind Alzheimer's disease. ${ }^{1}$ Eighty per cent of 'accidental' drug intoxication deaths and $90 \%$ of corresponding undetermined intent deaths, among the population 15 years and older, were assumed to be death from drug self-intoxication (DDSI). With methodology the same, the latest data from the U.S. Centers for Disease Control and Prevention revealed that combined non-suicide DDSI and suicide SIM exceeded diabetes mortality with respective rates of 26.1 versus 24.7 per 100000 in 2015 and 29.1 versus 24.8 in 2016 (figure 1). ${ }^{4}$ Moreover, SIM disproportionately affects younger individuals, leading to greater attributable years of life lost. ${ }^{2}$ The rate of SIM has climbed inexorably since 2000 and was $80 \%$ higher by 2016 . For men, the excess of deaths from SIM versus diabetes was evident by 2002 , and the rate ratio rose from 1.0 in 2000 to 1.5 in 2016. Diabetes mortality for women exceeded SIM over the entire observation period, but the rate ratio decreased from 4.1 in 2000 to 1.4 in 2016 .
Our conceptualisation of SIM encompasses all drug self-intoxication deaths arising from purposeful behaviours, which medical examiners and coroners label as 'accident' (unintentional) or 'undetermined' (evidence suggests equal plausibility for two or more manners of death), as well as all suicides (including 'intentional' fatal drug intoxications). ${ }^{3}$ SIM is intended to promote prevention and earlier interventions through recognising that common antecedent risk factors exist (eg, trauma, mental health disorders) and may be more precisely defined and targeted without sacrificing parallel efforts to discern vulnerabilities that are distinct for suicide versus unintentional self-injury.

Suicides using opioids and other drugs are under-reported due to manner of death determinations made by medical examiners and coroners. ${ }^{5}$ Recent findings from our two complementary analyses of microdata from the U.S. National Violent Death Reporting System underscore that the bar to designate suicide as the manner of death from drug intoxication is notably higher than for other common causes. ${ }^{67}$ Among drug-related suicides, documentation of a psychiatric history (especially an authenticated note expressing intent) was significantly more frequent than for suicides by firearms or by hanging/suffocation, indicating the need for more affirmative corroborating data before medical examiners and coroners label drug deaths as suicides. Complicating ascertainment, such evidence manifested in less than one-third of suicide cases.

These findings are problematic because surging opioid-related deaths are overwhelming the resources of many medical examiner/coroner offices and communities, with the drug intoxication death rate increasing more than threefold between 2000 and 2016, from 6.2 to 19.7 per 100000 population. ${ }^{4}$ They point to the uncertain accuracy of available surveillance data, and have serious implications for developing and implementing effective prevention and intervention strategies. Despite the higher case:fatality ratio for suicide by firearm or hanging, drug ingestion remains the most common form of attempted suicide. ${ }^{8}$ Readily available, potent heroin (often contaminated with fentanyl) is particularly lethal, which may serve to increase the case:fatality ratio of both suicide attempts and recurring drug ingestions that were intended to be intoxicating but not fatal.

Medical examiners and coroners use 'accident' primarily, and 'undetermined' much less frequently, as their defaults when assigning manner of death to fatal drug intoxications. ${ }^{9}$ Drug deaths of persons who were depressed, injecting heroin and drinking 


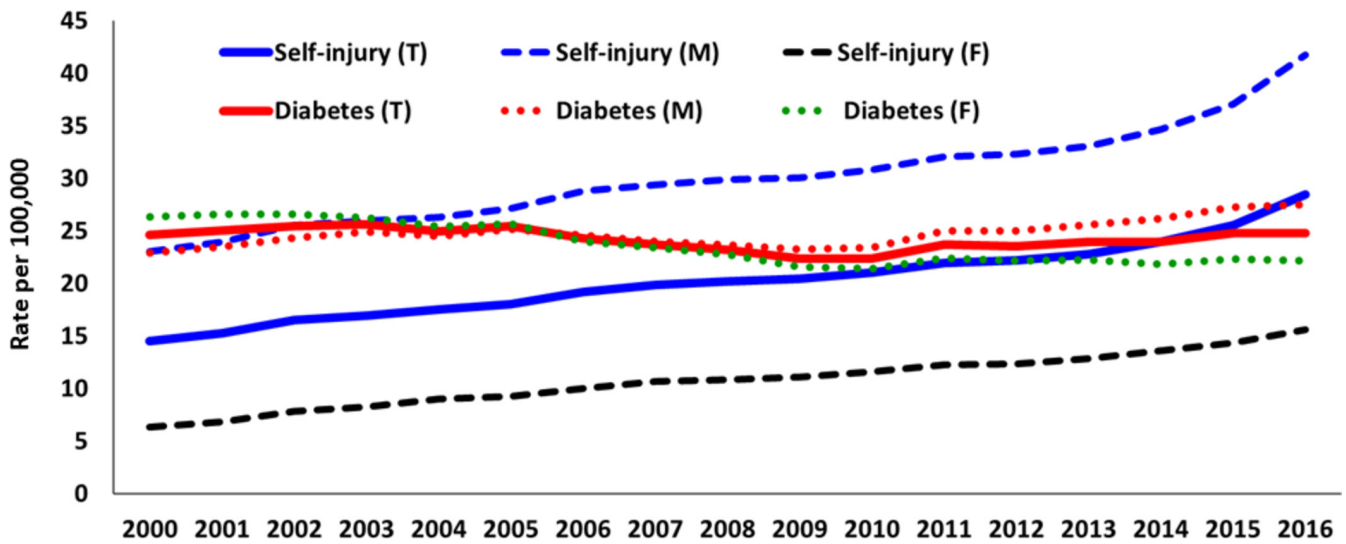

Figure 1 Crude mortality rates for self-injury and diabetes by sex, USA, 2000-2016.

alcohol, and who left a suicide note are labelled 'suicide' (figure 2). Deaths of persons who were depressed, injecting heroin and drinking alcohol, but had left no note typically are labelled 'accident'. Classifying the latter as accidental or unintentional is aetiologically misleading, however, since most injection opioid users knowingly engage in a pattern of repetitive self-harm associated with significant morbidity and mortality. ${ }^{310}$ Together with misclassification of drug-related suicides, this mischaracterisation profoundly understates-and masks-the true national burden of deaths arising from self-injurious behaviours.

In order to provide an accurate accounting of SIM, there is a fundamental need to focus attention on the antecedent circumstances of individual deaths, including capture of any corroborative behavioural evidence in drug intoxication cases, such as

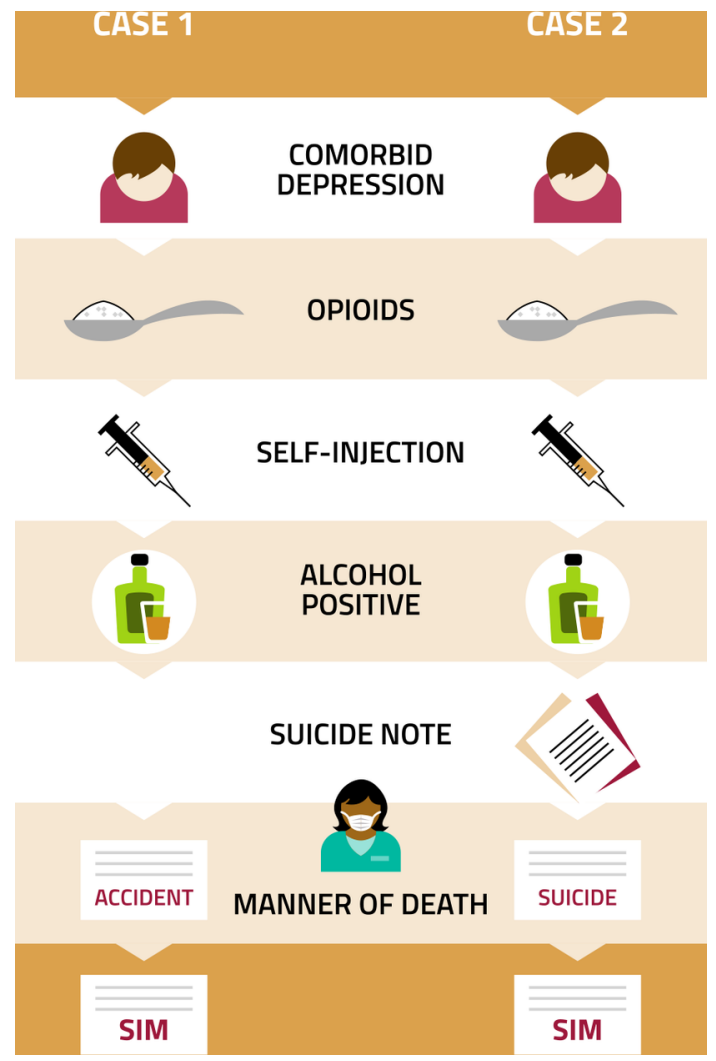

Figure 2 Two hypothetical cases of self-injury mortality (SIM). SIM can be operationalised as a composite of suicides by any method and estimated non-suicide deaths from drug self-intoxication. ${ }^{3}$ doctor or pharmacy shopping for prescription opioids, lethal intoxication by illicit drugs and drug paraphernalia at the death scene. Although U.S. medicolegal death investigations must meet statutory criminal justice obligations, they also yield essential data that serve as the foundation for understanding suicides, a latent or silent epidemic, as well as drug-intoxication deaths whose manners currently are classified as accidental and undetermined. After declining by 19\% between 1986 and 2000, the US suicide rate was 34\% higher in 2016 than in 2000 and has risen monotonically since $2005 .{ }^{4}$ Operationalisation of the data elements needed to characterise the antecedent behavioural and social bases of drug-related SIM could be used to establish standards for American medical examiners and coroners to identify and document psychiatric and substance use histories (eg, hospitalisations; data from prescription monitoring programmes), and to provide further insights needed to develop preventive interventions.

Medical examiners/coroners, clinicians and researchers have used intent to separate suicides from accidental or undetermined deaths. Determining intent requires divining proximal, individual motivations and immediate precursors, rather than considering fundamental population-level risk factors and antecedent individual-level vulnerabilities - the second set of variables essential for identifying potentially modifiable risks (eg, substance use, untreated mental disorder) and non-modifiable vulnerabilities (eg, a history of prior trauma or adversities). Such knowledge is needed to develop and institute effective prevention strategies. Facing similar social and psychologically complex health problems, the USA has initiated and sustained successful broad-based prevention efforts that have reduced deaths from cardiovascular diseases, smoking-related lung cancer, HIV and motor vehicular injury-given both necessary epidemiological understanding to define the problem and sufficient political will to address it. Without the former, it is impossible to build the latter. ${ }^{11} 12$

Mental health and substance use treatment services offer downstream interventions that may prevent drug-related fatalities, ${ }^{13}$ and readily available naloxone serves as an immediate rescue measure in the USA. As yet, they have not countered the surging numbers of self-injury fatalities. There is an urgent need to coalesce and coordinate upstream efforts through governmental policies and community prevention initiatives. However, such efforts often are siloed despite the common economic, social and clinical factors that precede deaths now classified as unintentional versus intentional. ${ }^{2} 1014$ Development of strategies for prevention will be facilitated by focusing on factors that are common risks for diverse outcomes. In addition to using SIM as 
the embracing construct that captures the fatal actions of those who have killed themselves, whether with declared intent or through imperilling self-injurious behaviours, first steps should include the standardisation of terminology, definitions, practices and training, ${ }^{515}$ and the building of coalitions that engage the diverse spectrum of community and professional stakeholders ${ }^{12}$ seeking to stem the rising tide of these premature deaths. Like premature mortality frequently associated with diabetes, deaths from self-injurious behaviours are preventable.

The high and escalating magnitude of the opioid mortality epidemic in the USA, in concert with cognisance of a simultaneous suicide epidemic, motivated the conceptualisation of DDSI ${ }^{10}$ and the associated enhanced category of SIM. ${ }^{3}$ We believe both concepts can be applied internationally, within constraints inherent in prevailing sociocultural, economic, political, epidemiological and medicolegal heterogeneity.

\section{What is already known on this subject?}

- There is a burgeoning epidemic of mortality from opioid and other drug intoxication in the USA.

- The suicide rate is also rising.

\section{What this study adds?}

- Collectively representing self-injury mortality, suicides and estimated non-suicide drug self-intoxication deaths have surpassed diabetes mortality.

- Turning the tide will require coalescence and coordination of upstream efforts through both governmental policies and community prevention initiatives, with a focus on common risks for diverse outcomes.

Acknowledgements The authors thank Sandra L Putnam for helpful comments on a previous version of the manuscript, and Ted R Miller and Joey Dacanay for their technical assistance in the preparation of figure 2 .

Contributors IRHR conceived the manuscript and obtained the data, and all authors contributed equally in the writing.

Funding This work was supported by Grants R49CE002109 and R49CE002093 from the National Center for Injury Prevention and Control of the Centers for Disease Control and Prevention.

Disclaimer The views expressed are those of the authors and do not necessarily represent the position or policy of the U.S. Centers for Disease Control and Prevention or the U.S. Government.
Competing interests None declared.

Patient consent Not required.

Provenance and peer review Not commissioned; internally peer reviewed.

Data sharing statement The data were extracted from a publicly accessible database. Centers for Disease Control and Prevention, Wide-ranging Online Data for Epidemiologic Research (https://wonder.cdc.gov/controller/datarequest/D67).

Open access This is an Open Access article distributed in accordance with the Creative Commons Attribution Non Commercial (CC BY-NC 4.0) license, which permits others to distribute, remix, adapt, build upon this work non-commercially, and license their derivative works on different terms, provided the original work is properly cited and the use is non-commercial. See: http://creativecommons.org/ licenses/by-nc/4.0

\section{REFERENCES}

1 Kochanek KD, Murphy S, Xu J. Mortality in the United States, 2016. NCHS Data Brief 2017;293:1-8

2 Case A, Deaton A. Mortality and morbidity in the 21st century. Brookings Pap Econ Activity Spring. 2017. https://www.brookings.edu/wp-content/uploads/2017/08/ casetextsp17bpea.pdf

3 Rockett IR, Lilly $\mathrm{CL}$, Jia $\mathrm{H}$, et al. Self-injury mortality in the United States in the early 21 st century: a comparison with proximally ranked diseases. JAMA Psychiatry 2016:73:1072-81.

4 Centers for Disease Control and Prevention. Wide-ranging Online Data for Epidemiologic Research. http://wonder.cdc.gov/controller/datarequest/D67

5 Stone DM, Holland KM, Bartholow B, et al. Deciphering suicide and other manners of death associated with drug intoxication: a Centers for Disease Control and Prevention consultation meeting summary. Am J Public Health 2017:107:1233-9.

6 Rockett IRH, Caine ED, Connery HS, et al. Discerning suicide in drug intoxication deaths: paucity and primacy of suicide notes and psychiatric history. PLoS One 2018;13:e0190200

7 Rockett IRH, Caine ED, Stack S, et al. Method overtness, forensic autopsy, and the evidentiary suicide note: a multilevel National Violent Death Reporting System analysis. PLoS One 2018;13:e0197805.

8 Miller M, Azrael D, Barber C. Suicide mortality in the United States: the importance of attending to method in understanding population-level disparities in the burden of suicide. Annu Rev Public Health 2012:33:393-408.

9 Warner M, Paulozzi LJ, Nolte KB, et al. State variation in certifying manner of death and drugs involved in drug intoxication deaths. Acad Forensic Pathol 2013;3:231-7

10 Rockett IR, Smith GS, Caine ED, et al. Confronting death from drug selfintoxication (DDSI): prevention through a better definition. Am J Public Health 2014;104:e49-e55.

11 Caine ED. Forging an agenda for suicide prevention in the United States. Am J Public Health 2013:103:822-9.

12 Lytle MC, Silenzio VM, Caine ED. Are there still too few suicides to generate public outrage? JAMA Psychiatry 2016;73:1003-4.

13 Oquendo MA, Volkow ND. Suicide: a silent contributor to opioid-overdose deaths. N Engl J Med 2018;378:1567-9.

14 McClure RJ, Mack K, Wilkins N, et al. Injury prevention as social change. Inj Prev 2016;22:226-9.

15 Hanzlick RL, Goodin J, Haden-Pinneri K. Mind your manners: 20 years later. Acad Forensic Pathol 2015;5:380-95. 